\title{
A combined prosodic and linguistic treatment approach for language-communication skills in children with autism spectrum disorders: A proof-of-concept study
}

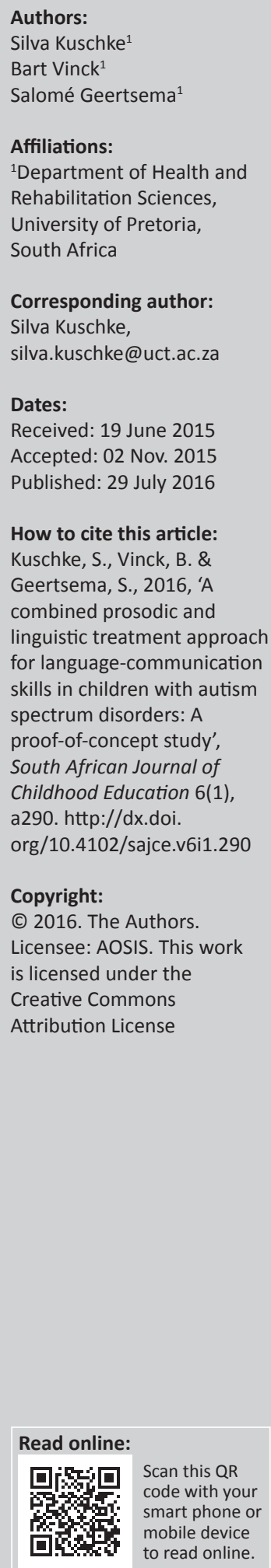

\begin{abstract}
This study aimed to determine whether the use of prosodically varied speech within a traditional language therapy framework had any effect on the listening skills, pragmatic skills and social interaction behaviour of three children with autism spectrum disorder (ASD). A single participant multiple baseline design across behaviours was implemented. Three participants with ASD were selected for this research. The listening skills, pragmatic skills and social interaction behaviour of the participants were compared before treatment, after a 3-week period of treatment and after a 2-week withdrawal period from treatment, utilising prosodically varied speech within a traditional language therapy approach. Statistical significance was not calculated for each individual due to the limited data, but visual inspection indicated that all the participants showed positive behavioural changes in performance across all areas after 3 weeks of treatment, independent of their pre-treatment performance level. The use of prosodically varied speech within a traditional language therapy framework appears to be a viable form of treatment for children with ASD.
\end{abstract}

\section{Introduction}

Children with autism spectrum disorder (ASD) are strongly influenced by sensory information from the environment, including auditory stimuli (Schafer et al. 2013). Processing of auditory information is essential to functioning and learning in the classroom. Children with ASD exhibit abnormal behavioural performance on auditory-based tasks, especially in the presence of background noise (Corbett \& Constantine 2006; Tomchek \& Dunn 2007). An analysis of profiles completed by 400 parents of children with ASD revealed that $58 \%-79 \%$ of the respondents indicated distractibility or inability to function in noisy environments, unresponsiveness to discriminative auditory stimuli and difficulty in attending auditory information (Tomchek \& Dunn 2007). One of the most significant predictors of educational performance in children with ASD is the challenge of auditory filtering, which is the ability to hear speech stimuli, complete tasks and function in the presence of background noise (Ashburner, Rodger \& Ziviani 2008).

\section{The need for special education of children with autism spectrum disorder}

Children with disabilities form a significant population within public education schools. In the United States, there are reportedly 5.8 million children with disabilities receiving services under the American Individuals with Disabilities Education Improvement Act (IDEIA) in public schools, with over 3.4 million of these students spending $80 \%$ or more of the school day in general education classrooms (Data Accountability Centre 2007). In South Africa, statistics indicate that there are approximately 467000 children with disabilities, of which only $4.3 \%$ are accessing early learning facilities (Household Survey 2010). Inclusive Education Law in South Africa stipulates that all students have the right to receive an appropriate education in the least restrictive environment. Students may not be excluded from educational services due to a disability, no matter how severe the disability may be (Education White Paper 6 2001). Special education theory is located within a predominantly functionalist paradigm and is concerned with both learners who experience learning breakdown and those who are regarded as disabled (Education White Paper 6 2001). Children with ASD often experience difficulty adapting to a mainstream school environment, because their behaviour is so obviously different from that of typically developing children (Whitman 2004).

Individuals with ASD display many challenging behaviours, which decreases their ability to learn via conventional teaching methods. These challenges include visual thinking, more time 
to process information, decreased ability to generalise learning, decreased attention to tasks, sensory problems, a lack of flexibility and extreme literality (Williams, Tutty \& Grinnel 1995). The educational implications of ASD within the Triad of Impairments (Wing 1988) are far-reaching and encompass many challenges for mainstream school teachers. Challenges in social interaction within the classroom environment include a low tolerance of peer group, dislike of sharing and taking turns, little or no empathy for others and social aloofness (Lamers \& Hall 2003). Simple social actions such as lining up are often a complicated process (Lord 2000). Communication challenges in the classroom include a lack of motivation to communicate, limited understanding of the attempts of others, minimal enjoyment of shared social situations and limited conversational skills (Lord \& Corsello 2005). Challenges regarding rigidity of thought and behaviour include difficulty with pretend play or dramas, repetitive play patterns and difficulties with judging the cause and effect of their own behaviour (Schafer et al. 2013). Specific clinical characteristics that may influence performance in a classroom setting include distractibility, disorganisation, listening difficulties, inattention to tasks and limited or heightened alertness (Schafer et al. 2013). When children exhibit several of these clinical characteristics, which directly impact their educational performance, they may qualify for special education services for ADHD under the eligibility category of 'other health impairment' (Individuals with Disabilities Education Act 2004).

Given the increased recognition of ASD in children with average cognitive ability and the emphasis on the inclusion of students with special needs in regular education classrooms (Williams, Johnson \& Sukhodolsky 2005), schools and clinicians are increasingly called upon to enhance the social skills of school-age children with ASD (White, Keonig \& Seahill 2006). These children need to be taught appropriate skills for interacting and communicating with others, as well as modifying their behaviour to comply with acceptable social norms (Zager 2005).

\section{Prosodic aspects of speech}

Prosody is an element of language and communication that utilises variations of duration, intensity and pitch, to change emphasis, stress, rhythm and intonation (Wagner \& Watson 2010). Prosody in speech is a by-product of language, not a construct upon which it is built (Patel 2007). Prosody is a complex temporal organisation of acoustic events, perceived mainly through the auditory modality, and possesses inherent qualities that may be used to aid in very specific aspects of language development (Thaut 2003).

Research suggests that rhythm, tempo, melody and intonation may provide a sense of structure to facilitate perception and production of expressive language in children with ASD (Patel 2007). Boucher, Collis and Lewis (2000) found that children with ASD were equal to their typically developing peers in the ability to label six basic emotions based on the affective prosody of single-word utterances (e.g. days of the week). Affective prosody refers to a speaker varying the pitch and duration of an utterance to indicate his or her emotional state (Grossman et al. 2010). Communicative functions in which prosodic elements play an important part include pragmatic functions such as the use of stress to signal an important or contrastive word, usually indicating a specific emotive response, as in the utterance: 'I wanted BLUE socks' where 'blue' is stressed to suggest that this is an important word, probably contrasting with a previously mentioned colour (McCann \& Peppe 2003). This use is manifested as differentiation between stressed and unstressed words or syllables by variation in speech intensity and duration (McCann \& Peppe 2003).

\section{Perception of prosodic elements of speech}

To date, the majority of investigations into prosody in ASD have focused upon expressive abilities, and surprisingly little is known about the ability of individuals with ASD to interpret prosodic cues in the speech of others (Paul et al. 2005). In a review article, McCann and Peppe (2003) concluded that the existing research literature showed inconsistent evidence of the processing of spoken prosody in children with ASD.

Aside from the auditory processing challenges facing the child with ASD, they also display certain skills in this regard. One finding that stands out in auditory research in ASD is that many individuals have enhanced pitchdiscrimination and pitch-memory abilities (Ouimet et al. 2012). The use of stress variation and intonation in a spoken utterance may help to stimulate a form of auditory processing in children with ASD which, though not typical, could aid in extracting meaning from auditory stimuli (Caria, Venuti \& de Falco 2011). Auditory-based training paradigms appear to have a positive effect on speech processing and on speech production in non-verbal children with ASD (Ouimet et al. 2012).

However, despite the existence of strengths regarding auditory processing in individuals with ASD, they generally show diminished processing of social and complex sounds such as speech (Ouimet et al. 2012). Possible reasons for this may be the limited use of these superior processing skills, because there is minimal variation of prosodic elements in conversational discourse and traditional therapy approaches, and thus these strengths are not applied to aid the child in a social communication situation (Heaton 2005; Ingersoll \& Shreibman 2006). An integrated approach in which language therapy is combined with prosodically varied speech may enhance the effect of language treatment.

Results from research regarding the neurological foundations of processing melodic and rhythmic stimuli suggest that specific elements of prosody, such as variations in intonation and stress, may stimulate areas of the brain often found to be atypical in individuals with ASD (Boddaert 2004). Elements of prosody such as intonation and stress variation therefore warrant research into a different treatment approach to stimulate atypical but more effective processing (Gervais 2004). 
This study aimed to determine whether the use of prosodically varied speech within a traditional language therapy framework had any effect on the listening skills, pragmatic skills and social interaction behaviour of three children with ASD.

\section{Method}

\section{Research design}

A single-participant multiple baseline design across behaviours was used to provide 'proof of concept' (Smith et al. 2007). Figure 1 depicts the phases of the research.

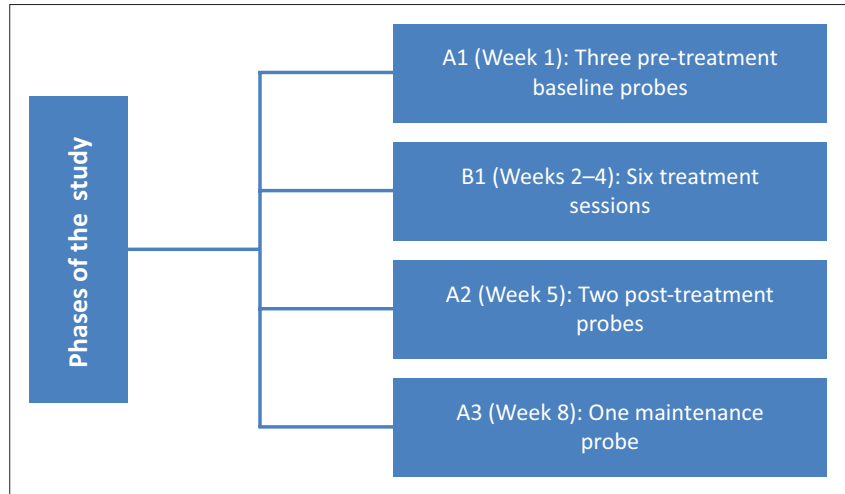

Source: Kuschke, S., 2015, 'A prosodic and linguistic treatment approach for languagecommunication skills in children with autism spectrum disorders', Master of communication pathology thesis, University of Pretoria

FIGURE 1: Schematic presentation of the research design.

\section{Participants}

Three participants were recruited from a school which accommodates children with ASD by means of purposive sampling. Participants had to speak either English or Afrikaans as first language. All participants included in this study had to display deficits in listening skills, pragmatic skills (discourse) and social interaction. All the participants had to be diagnosed with ASD. Diagnosis in all cases was according to the APA (1994), as the APA (2013) had not been published when this study commenced. In addition, participants needed to have some degree of functional speech and minimal 'hyperhearing'. The chronological age of the participants had to be between 6:0 and 8:11 years (school-going age). See Table 1 for a description of the profiles of the participants. Participants were not to receive additional speech therapy during the research period.

\section{Material}

The material and activities that were used during the interaction sessions as well as the aim(s) of each activity are described in Table $2 \mathrm{a}$ and Table $2 \mathrm{~b}$. The prosodically varied speech procedures are described in Appendix 1. Phrases were intoned on just two pitches; melodic contour was determined by the natural prosody of speech.

TABLE 1: Profiles of participants.

\begin{tabular}{llllll}
\hline Participant & Sex & Chronological age & Age at diagnosis & Home language & $\begin{array}{l}\text { Degree of ASD (as determined by } \\
\text { the ADOS-G) }\end{array}$ \\
\hline Participant 1 & Male & 6 years 7 months & 3 years 2 months & Afrikaans & Moderate \\
Participant 2 & Male & 7 years 4 months & 6 years 1 months & English & Severe \\
Participant 3 & Male & 8 years 4 months & 5 years 6 months & English & Moderate \\
\hline
\end{tabular}

Source: Kuschke, S., 2015, 'A prosodic and linguistic treatment approach for language-communication skills in children with autism spectrum disorders', Master of communication pathology thesis, University of Pretoria

TABLE 2a: Material used during treatment sessions.

\begin{tabular}{|c|c|c|c|}
\hline Treatment aims & Justification & Procedures & Material \\
\hline $\begin{array}{l}\text { To facilitate whole-body } \\
\text { listening skills throughout the } \\
\text { treatment sessions. }\end{array}$ & $\begin{array}{l}\text { Listening is the ability to attune to important } \\
\text { auditory information and to ignore unnecessary } \\
\text { information. The attuning function of listening plays } \\
\text { a fundamental role in auditory processing and } \\
\text { attention span, both essential to the acquisition of } \\
\text { receptive language which is deficient in children } \\
\text { with ASD (Nwora \& Gee 2009). }\end{array}$ & $\begin{array}{l}\text { (Name of child), this is Nando the dog. } \\
\text { He will help us to listen well today. } \\
\text { Nando has big ears to listen (show ears) } \\
\text { and big eyes to look at me when I'm } \\
\text { speaking (show eyes). }\end{array}$ & Soft-toy dog. \\
\hline $\begin{array}{l}\text { To establish routine, to elicit a } \\
\text { response to greeting, to } \\
\text { facilitate joint attention and to } \\
\text { establish eye-contact. }\end{array}$ & $\begin{array}{l}\text { Young children with ASD typically exhibit core } \\
\text { deficits in social communication skills, particularly in } \\
\text { the areas of joint attention, reciprocity, eye-contact } \\
\text { and skills in functional and symbolic play (Veness } \\
\text { et al. 2012). }\end{array}$ & $\begin{array}{l}\text { A song based on a familiar tune was } \\
\text { sung at the beginning and a similar song } \\
\text { at the end of each session. Singing was } \\
\text { used, rather than simple chanting in } \\
\text { order to utilise the variations in pitch } \\
\text { provided by the melody. The therapist } \\
\text { began the song, after which the child } \\
\text { imitated each phrase. }\end{array}$ & $\begin{array}{l}\text { Greeting song: } \\
\text { Hello (child's name), (Hello- therapist's name) } \\
\text { How are you? (How are you?) } \\
\text { We will play together (We will play together) } \\
\text { You and I (You and I) } \\
\text { Good-bye song: } \\
\text { Bye-bye (child's name), (Bye-bye - therapist's } \\
\text { name) } \\
\text { You were good! (You were good!) } \\
\text { We played well together (We played well } \\
\text { together) } \\
\text { You and I (You and I) }\end{array}$ \\
\hline $\begin{array}{l}\text { To elicit object naming. The } \\
\text { therapist modelled the desired } \\
\text { response, after which the child } \\
\text { had to imitate the therapist. }\end{array}$ & $\begin{array}{l}\text { Among the earliest concerns of parents with } \\
\text { children with ASD are delays in speech and language } \\
\text { development, specifically the acquisition and } \\
\text { development of receptive and expressive language } \\
\text { (Guinchat et al. 2012). Object naming is also an } \\
\text { important aspect of pragmatic skills (Shipley \& } \\
\text { McAfee 2009), which are known to be impaired in } \\
\text { children with ASD (Grossman et al. 2010). }\end{array}$ & $\begin{array}{l}\text { (Name of child), I have five pictures } \\
\text { here. I want you to tell me what you see } \\
\text { on each picture. (If the child did not } \\
\text { spontaneously respond, a cue was given } \\
\text { by the therapist, using PVS: 'This is an } \\
\text { apple'). (See Appendix } 1 \text { for PVS } \\
\text { procedures). }\end{array}$ & Picture cards. \\
\hline $\begin{array}{l}\text { To facilitate non-verbal } \\
\text { imitation behaviour, as well as } \\
\text { taking turns. }\end{array}$ & $\begin{array}{l}\text { Atypical social interaction, which includes atypical } \\
\text { eye-gaze, imitation and social reciprocity, is a } \\
\text { hallmark of children with ASD (Guinchat et al. } \\
\text { 2012). }\end{array}$ & $\begin{array}{l}\text { Two empty coffee tins were used by the } \\
\text { therapist to create simple, rhythmic } \\
\text { patterns, which the child had to imitate } \\
\text { after listening to each rhythmic pattern } \\
\text { carefully. }\end{array}$ & Two empty coffee tins. \\
\hline
\end{tabular}


TABLE 2b: Material used during treatment sessions.

\begin{tabular}{|c|c|c|c|}
\hline Treatment aims & Justification & Procedures & Material \\
\hline $\begin{array}{l}\text { To facilitate following } \\
\text { one-step instructions. }\end{array}$ & $\begin{array}{l}\text { Receptive language, which includes following } \\
\text { instructions, is an important pre-cursor to } \\
\text { later academic success (Prelock \& Nelson } \\
\text { 2012). }\end{array}$ & $\begin{array}{l}\text { The therapist named the colour of each block, using PVS (see } \\
\text { Appendix 1). The child was then instructed to name the } \\
\text { colours of the blocks, as well as to follow commands ('give } \\
\text { me the blue block'). The command was intoned (said using } \\
\text { two different pitches; one low and one high). } \\
\text { Example: 'This is the yellow/blue/red/green block' (while } \\
\text { showing the appropriate block). Commands: 'Give me the } \\
\text { yellow/blue/red/green block'. }\end{array}$ & Brightly coloured building blocks. \\
\hline $\begin{array}{l}\text { To elicit picture } \\
\text { description and } \\
\text { expansion on a topic. }\end{array}$ & $\begin{array}{l}\text { Deficits in expressive language lead to } \\
\text { reduced social interaction with peers, as well } \\
\text { as poor pragmatic skills (Volkmar, Chawarska } \\
\& \text { Klin 2005). }\end{array}$ & $\begin{array}{l}\text { Drawing different shapes with crayons and stencils provided } \\
\text { the therapist with an opportunity to model a sentence or a } \\
\text { question using PVS, giving the child a chance to describe a } \\
\text { picture and expand on a topic. } \\
\text { Example: (Name of child), let us draw some pictures with } \\
\text { these stencils. Sentences were modelled, e.g. 'This is a } \\
\text { fishing boat', and then questions were intoned about the } \\
\text { picture, e.g. 'What kind of boat is this? 'What is it floating } \\
\text { on?' }\end{array}$ & Stencils, paper and crayons. \\
\hline $\begin{array}{l}\text { To teach grouping and } \\
\text { categorisation skills. }\end{array}$ & $\begin{array}{l}\text { As children with ASD reach school-going age, } \\
\text { delays in language-based tasks, such as } \\
\text { problem-solving and symbolic thinking, } \\
\text { become more apparent (Volkmar et al. 2005). }\end{array}$ & $\begin{array}{l}\text { 'This is an/a (apple/banana/grape/peach)'. } \\
\text { 'Give me the red/yellow/purple fruit'. } \\
\text { 'Where are all the apples/grapes/bananas?' } \\
\text { (See Appendix } 1 \text { for a description of the of the PVS } \\
\text { procedures used by the researcher). }\end{array}$ & Plastic fruit. \\
\hline $\begin{array}{l}\text { To teach requesting } \\
\text { behaviour. }\end{array}$ & $\begin{array}{l}\text { Verbal, as well as non-verbal requesting } \\
\text { behaviour of children with ASD seems to be } \\
\text { impaired. Requesting is an important skill for } \\
\text { the development of social-communicative } \\
\text { behaviour. }\end{array}$ & $\begin{array}{l}\text { The bubbles were shown to the child, while the therapist } \\
\text { waited for a request. If the child did not respond, a probing } \\
\text { question was intoned 'would you like to blow some } \\
\text { bubbles?' }\end{array}$ & Bubbles. \\
\hline $\begin{array}{l}\text { To describe events and } \\
\text { sequence actions. }\end{array}$ & $\begin{array}{l}\text { Expressive language behaviour such as } \\
\text { describing events in sequence is an important } \\
\text { indicator for the development of pragmatic } \\
\text { skills. }\end{array}$ & $\begin{array}{l}\text { '(Name of child), we are going to read from this book now'. } \\
\text { While the child paged through the book, the therapist } \\
\text { modelled an appropriate sentence, using PVS (e.g. 'Suzy fell } \\
\text { out of the tree'), after which the child had to imitate the } \\
\text { therapist. After each page, the therapist asked a probe- } \\
\text { question: e.g. 'what hap-pened to Suzy?' }\end{array}$ & A book containing large colourful pictures. \\
\hline $\begin{array}{l}\text { To facilitate role-play and } \\
\text { to teach object function. }\end{array}$ & $\begin{array}{l}\text { Theory of mind seems to be severely } \\
\text { impaired in children with ASD (Prelock \& } \\
\text { Nelson 2012). Role-play is an important tool } \\
\text { for improving theory of mind in children with } \\
\text { ASD. Knowing object functions is an } \\
\text { important pragmatic skill (Shipley \& McAfee } \\
\text { 2009). Deficits in theory of mind and } \\
\text { pragmatic skills complicate the ability of the } \\
\text { child with ASD to fully engage in the } \\
\text { give-and-take of conversational discourse } \\
\text { expected during social exchanges (Prelock \& } \\
\text { Nelson 2012). }\end{array}$ & $\begin{array}{l}\text { '(Name of child), Nando is very sick today; we need to help } \\
\text { him. You will be the doctor today - let us get everything you } \\
\text { need to help Nando'. 'This is the stethoscope/bandage/ } \\
\text { plaster'. } \\
\text { 'Listen to the heart with the stethoscope; close the scratch } \\
\text { with the plaster; put a bandage around Nando's paw. } \\
\text { Probe-questions: 'How will we close the scratch? What will } \\
\text { we use to listen to Nando's heart? Where must the bandage } \\
\text { go'? }\end{array}$ & Toy medical kit. \\
\hline $\begin{array}{l}\text { To re-direct the child's } \\
\text { attention to the current } \\
\text { task by using songs. }\end{array}$ & $\begin{array}{l}\text { It was noticed that the children sometimes } \\
\text { lost motivation to participate, and that } \\
\text { singing a song together re-focused their } \\
\text { attention to the task at hand. }\end{array}$ & $\begin{array}{l}\text { The therapist began the song, after which the child joined in. } \\
\text { '(Name of child), we are going to sing some songs now. I will } \\
\text { sing the song for you, and then we will sing the song } \\
\text { together, and then you must sing the song alone'. }\end{array}$ & Familiar nursery songs. \\
\hline
\end{tabular}

Source: Kuschke, S., 2015, 'A prosodic and linguistic treatment approach for language-communication skills in children with autism spectrum disorders', Master of communication pathology thesis, University of Pretoria

\section{Measures}

The following behavioural observation checklists were used to assess each participant during the three baseline probes, the two post-treatment probes and the maintenance probe:

- Listening Skills Observation Checklist (BLM G-5 2010), consisting of 11 behaviours.

- Assessment of Pragmatic Skills Checklist (Shipley \& McAfee 2009, form 8-7), consisting of 15 behaviours.

- Gilliam Autism Rating Scale (GARS - 2 2006), consisting of 14 stereotyped behaviours, 14 communication behaviours and 14 social-interaction behaviours.

The data collection was done during Week 1 (three pretreatment baseline probes), Week 5 (two post-treatment probes) and Week 8 (one maintenance probe) by means of videotaping behaviour and reactions during interaction sessions. All the assessment probes were watched, analysed and scored directly after each session by the researcher and an external rater. The external rater was a professionally trained speech-language pathologist with a specific interest in children with ASD. The three behavioural observation checklists were used to score behaviours and reactions relating to listening skills, pragmatic skills and social interaction behaviour.
The external rater was included for the specific purpose of recording data with the researcher. It is challenging to observe, participate and record data simultaneously; therefore, every interaction session with each participant was video-recorded (Uys 2002). All scores were assigned directly after watching the recordings of each session. The researcher and the external rater watched all the recorded sessions individually and scored behaviours according to the three behaviour checklists. The external rater scored the participants on a separate sheet, using a different room to watch the video recordings. For the listening skills and pragmatic skills checklists, a score of 1 was given if the behaviour was observed during the session, while a score of 0 was given if the behaviour was not observed during the session. For the GARS-2, a score of 1 was given if the behaviour was observed 0-2 times during the session; a score of 2 was given if the behaviour was observed 3-5 times during the session; a score of 3 was given if the behaviour was observed more than 5 times during the session, while a score of 0 was given if the behaviour was not observed during a session. The raw scores were converted to standard scores, and subsequently converted to a percentile for each participant. 


\section{Probe procedures}

Each participant was assessed independently. Assessment took place in the same room where treatment was provided. Only the participant and the researcher were present during interaction sessions. A number of activities were planned and appropriate materials were available to facilitate interaction (Table 2a and 2b). The materials included a soft-toy dog, picture cards, empty coffee tins, building blocks, stencils, plastic fruit, picture books, bubbles and a toy medical kit. Behaviour and reactions of each participant were assessed by means of the three behavioural observation checklists. The researcher initiated all activities, and each assessment session lasted approximately $30 \mathrm{~min}$. The video camera was set up in the corner of the room and switched on as each participant entered the room. All interaction sessions were videorecorded.

\section{Treatment procedures}

A large room was used, with minimal noise and distractions. Each participant was treated individually. Only the participant and the researcher were present during interaction sessions. A number of activities were planned and appropriate materials were available to facilitate interaction (Table $2 \mathrm{a}$ and $2 \mathrm{~b}$ ). The researcher briefly explained each activity to the participant by means of a visual timeline (pictures in sequence of the activities which would be done during that session), so as to put the participant at ease and to let him know what to expect during the session. The video camera was set up in the corner of the room and switched on as each participant entered the room. Each treatment session lasted approximately $30 \mathrm{~min}$. All interaction sessions were video-recorded.

\section{Results}

All raw scores were converted to percentages by dividing the raw score by the total number of items in the assessment scale and multiplying this score by 100 . In the case of the Autism Index, the percentile score for each participant was calculated according to the conversion tables in the GARS-2. A correlation calculation between the scores of the researcher and external rater for each item on each of the three behavioural checklists was used to determine the inter-rater reliability of the three baseline probes, the two post-treatment probes and the maintenance probe (Schiavetti \& Metz 2006). There was a direct correlation in the researcher's and external rater's scoring in $98.3 \%$ of the cases, as obtained by the Kappa statistical method. This was significant on a $95 \%$ level. The conclusion can therefore be made that there was a significant correlation between the two different raters. Statistical significance was not calculated for each individual due to the limited data. It is clear from 'eyeball estimation' (inspecting data and quickly making an educated guess about the approximate magnitude of relevant statistics - Hurlburnt 2007), however, that all the participants showed a positive change in performance across all areas, regardless of their pre-treatment performance level. Table 3 presents the overall performance of each participant after 3 weeks of treatment.
TABLE 3: Overall performance of each participant after 3 weeks of treatment.

\begin{tabular}{llll}
\hline Area & $\begin{array}{l}\text { Week 1 (pre- } \\
\text { treatment average) }\end{array}$ & $\begin{array}{l}\text { Week 5 (post- } \\
\text { treatment average) }\end{array}$ & Change in behaviour \\
\hline Listening skills & $27.2 \%$ & $54.5 \%$ & $27.3 \%$ \\
Pragmatic skills & $33.3 \%$ & $66.7 \%$ & $33.3 \%$ \\
Autism Index & 84 th percentile & 35 th percentile & 49 percentile points \\
Listening skills & $27.2 \%$ & $54.5 \%$ & $27.3 \%$ \\
Pragmatic skills & $20 \%$ & $66.7 \%$ & $46.7 \%$ \\
Autism Index & 98 th percentile & 96 th percentile & 2 percentile points \\
Listening skills & $36.4 \%$ & $54.5 \%$ & $18.1 \%$ \\
Pragmatic skills & $60 \%$ & $66.7 \%$ & $6.7 \%$ \\
Autism Index & 87 th percentile & 39 th percentile & 48 percentile points \\
\hline
\end{tabular}

Source: Kuschke, S., 2015, 'A prosodic and linguistic treatment approach for languagecommunication skills in children with autism spectrum disorders', Master of communication pathology thesis, University of Pretoria

\section{Discussion}

The main aim of this study was to evaluate whether the use of a combined prosodic and linguistic approach would have any effect on the listening skills, pragmatic skills and social interaction behaviour of three young children with ASD.

The results were indicative of positive behavioural change in all three communication-related areas (listening skills, pragmatic skills and social interaction behaviour) for all three participants. All of the participants showed a marked decline in performance after the withdrawal phase. This decline in performance may be attributed to the fact that the participants had a 2-week school holiday and were not in a structured classroom environment where they might have had the opportunity to maintain new skills learned during treatment. Many studies have reported on the limited ability of children with ASD to generalise skills, especially with regard to social reciprocity (Leach \& LaRocque 2006), reciprocal imitation skills (Ingersoll \& Schreibman 2006), expressive prosody (Bellon-Harn, Harn \& Watson 2007) and speech output (Wan et al. 2011). On the other hand, the average scores for all of the participants in all the communication areas after the withdrawal phase were higher than their pre-treatment probes, indicating that they retained some of the skills learned during treatment. This finding is in line with literature reports indicating that children with ASD display receptive prosodic preferences (Lamers \& Hall 2003) can recall stressed words better than unstressed words after intervention (Smith \& Robb 2005), and are more inclined to respond to and retain melody- and rhythm-based information (Wan et al. 2011).

The positive change in behaviour of all three participants in the different communication-related areas is in line with recent findings of similar studies. Results from research on auditory factors in ASD indicate that many individuals have exceptional pitch-discrimination abilities (Heaton et al. 2008) and generally show limited processing of social and more complex sounds such as connected speech (Ouimet et al. 2012). Findings from the current study demonstrated that the use of prosodically varied speech intervention within the framework of a traditional language treatment approach led not only to positive change directly after the treatment phase, but also to a degree of maintained behaviour after the 2-week withdrawal phase. A recent study investigating the 
efficacy of melodic-based communication therapy to elicit speech output in non-verbal children with ASD (Sandiford, Mainess \& Daher 2013) reported that both taught and untaught words were generalised to the home environment. The ability of children with ASD to generalise skills taught using melodic-based stimuli is further supported by other recent findings indicating that skills taught using intonation are generalised to the production of words not taught during therapy (Wan et al. 2011).

An important finding is that the behavioural change did not occur in a linear fashion but rather as a continuous process where the interdependency of the skills becomes clear. Because treatment occurred within a combined prosodic and linguistic framework, the areas that were targeted were expected to change in a positive way (Prelock \& Nelson 2012).

\section{Limitations and future research}

Due to the nature of the research design (pre-test, post-test), and the fact that a combined prosodic and linguistic approach was used, no final conclusions can be drawn in terms of the efficacy of using specifically prosodically varied speech for the treatment of communication-related skills in children with ASD. A number of problems were experienced with the selection of the participant sample. Although the sample was criterion-based, it was not possible to select a homogeneous group, as the ASD population is heterogeneous. A large sample could not be included, as each participant had to be treated during school hours in the treatment period. A control group was not included in this study. This would have strengthened the research, as the influence of maturation and other external variables could have been controlled.

For the purpose of this study, the listening and pragmatic behaviours were only scored once if they were observed during the probe sessions. The frequency of the behaviour elicited during the sessions was not measured. Therefore, a maximum score of 11 for listening skills and 15 for pragmatic skills could be obtained. This analysis procedure obscured subtle changes in behaviour. This research project was an exploratory proof-of-concept study and any positive changes in the behaviour of the participants cannot be ascribed unequivocally to the specific intervention but may only mean that the use of prosodically-varied speech within a traditional language treatment framework did not harm the participants or inhibit their performance.

The intervention addressed three communication-related skills, namely, listening, pragmatic and social-interaction skills. Other communication areas, such as receptive language and social emotional skills, were not addressed directly. A study focusing on facilitating receptive language skills and social emotional skills using prosodically varied speech would be valuable.

The methodology used in this research required individual participants, and therefore it is difficult to generalise the results to a larger population. Another project could investigate the use of a combined prosodic and linguistic approach within a group context. Due to the fact that only three children with ASD were included in the study, the findings lack external validity. Prosodically varied speech could be used in other cultural and social contexts to determine its external validity. Although many communication-related behaviours were elicited in this study, evaluation of daily interactions was limited. Future research could expand the evaluation protocol in order to includea greater variety of behaviours in each communicationrelated area.

\section{Acknowledgements Competing interests}

The authors declare that they have no financial or personal relationships which may have inappropriately influenced them in writing this article.

\section{Authors' contributions}

S.K. was the main contributing author of this article and submitted the article in partial fulfilment of the degree Master of Communication Pathology. B.V. was the main supervisor of the masters project and S.G. was the co-supervisor of the masters project and edited multiple drafts of the manuscript and subsequent article.

\section{References}

American Psychiatric Association, 1994, Diagnostic and Statistical Manual of Mental Disorders, 4th edn., American Psychiatric Association, Virginia.

American Psychiatric Association, 2013, Diagnostic and Statistical Manual of Mental Disorders, 5th edn., American Psychiatric Association, Virginia.

Ashburner, J., Rodger, S. \& Ziviani, J., 2008, 'Sensory processing and classroom emotional, behavioural, and educational outcomes in children with autism spectrum disorder', American Journal of Occupational Therapy 62, 564-573.

Bellon-Harn, M.L., Harn, W.E. \& Watson, G.D., 2007, 'Targeting prosody in an eightyear-old child with high-functioning autism during an interactive approach to therapy', Child Language Teaching and Therapy 23(2), 157-179. http://dx.doi. therapy', Child Language Teaching
org/10.1177/0265659007076292

Boddaert, N., 2004, 'Perception of complex sounds in autism: Abnormal auditory cortical processing in children', American Journal of Psychiatry 161, 2117-2120. http://dx.doi.org/10.1176/appi.ajp.161.11.2117

Boucher, J., Lewis, V. \& Collis, G.M., 2000, 'Voice processing abilities in children with autism, children with specific language impairments, and young typically developing children', Journal of Child Psychology and Psychiatry 41(7), 847-857.

Caria, A., Venuti, P. \& de Falco, S., 2011, 'Functional and dysfunctional brain circuits underlying emotional processing of music in autism spectrum disorders', Cerebral Cortex 21, 2838-2849. http://dx.doi.org/10.1093/cercor/bhr084

Corbett, B. \& Constantine, L., 2006, 'Autism and attention deficit hyperactivity disorder: Assessing attention and response control with the integrated visual and auditory continuous performance test', Child Neuropsychology 12, 335-348. http://dx.doi.org/10.1080/09297040500350938

Data Accountability Centre, 2007, United States Department of Education.

Education White Paper 6, 2001, Building an inclusive education and training system, Department of Education, Pretoria.

Gervais, H., 2004, 'Abnormal cortical voice processing in autism', Natural Neuroscience 7, 801-802. http://dx.doi.org/10.1038/nn1291

Gilliam, J., 2006, Gilliam autism rating scale, 2nd edn., Pro-ed, Austin, TX.

Grossman, R.B., Bemis, R.H., Skwerer, D.P. \& Tager-Flusberg, H., 2010, 'Lexical and affective prosody in children with high-functioning autism', Journal of Speech, Language and Hearing Research 53, 778-793. http://dx.doi.org/10.1044/1092 4388

Guinchat, V., Chamak, B., Bonniau, B., Bodeau, N., Perisse, D., Cohen, D. et al., 2012, Very early signs of autism reported by parents include many concerns not specific to autism criteria', Research in Autism Spectrum Disorders 6, 598-601. http://dx. doi.org/10.1016/j.rasd.2011.10.005

Heaton, P., 2005, 'Interval and contour processing in autism', Journal of Autism and Developmental Disorders 8, 1-7. http://dx.doi.org/10.1007/s10803-005-0024-7 
Heaton, P., Hudry, K., Ludlow, A. \& Hill, E., 2008, 'Superior discrimination of speech pitch and its relationship to verbal ability in autism spectrum disorders', Cognitive pitch and its relationship to verbal ability in autism spectrum disorders', Cognitive
Neuropsychology 25, 771-782. http://dx.doi.org/10.1080/02643290802336277

Helm-Estabrooks, N., Nicholas, M., \& Morgan, A., 1989, Melodic intonation therapy. Pro-Ed., Inc. Austin, TX.

Hurlburnt, R.T., 2007, Neil J. Salkind (ed.), 'Eyeball Estimation', Encyclopedia of measurement and statistics, 336-337.

Individuals with Disabilities Education Improvement Act, 2004, PL 108-446

Ingersoll, B. \& Shreibmann, L., 2006, 'Teaching reciprocal imitation skills to young children with autism using a naturalistic behavioural approach: Effects on language, pretend play, and joint attention', Journal of Autism and Developmental Disorders 36(4), 487-505. http://dx.doi.org/10.1007/s10803-006-0089-y

Kuschke, S., 2015, A prosodic and linguistic treatment approach for languagecommunication skills in children with autism spectrum disorders. Master of communication pathology thesis. University of Pretoria.

Lamers, K. \& Hall, L.J., 2003, 'The response of children with autism to preferred prosody during instruction', Focus on Autism and Other Developmental Disabilities 18(2), 93-102. http://dx.doi.org/10.1177/108835760301800203

Leach, D. \& LaRocque, M., 2009, 'Increasing social reciprocity in young children with autism', Intervention in School and Clinic 46, 150-156. http://dx.doi.org/ $10.1177 / 1053451209349531$

Lord, C., 2000, 'Commentary: Achievements and future directions for intervention research in communication and autism spectrum disorders', Journal of Autism and Developmental Disorders 30, 393-398. http://dx.doi.org/10.1023/A 1005591205002

Lord, C. \& Corsello, C., 2005, 'Diagnostic instruments in autism spectrum disorders', in F.R. Volkmar, R. Paul, A. Klin \& D. Cohen (eds.), Handbook of autism and pervasive developmental disorders, 3rd edn., pp. 730-771, John Wiley \& Sons Inc.

McCann, J. \& Peppe, S., 2003, 'Prosody in autism spectrum disorders: A critical review', International Journal of Communication Disorders 38(4), 325-350. http:// dx.doi.org/10.1080/1368282031000154204

Nwora, A.J. \& Gee, B.M., 2009, 'A case study of a five-year-old child with pervasive developmental disorder-not otherwise specified using sound-based interventions', Occupational Therapy International 16(1), 25-43. http://dx.doi.org/10.1002/oti.263

Ouimet, T., Foster, N.E.V., Tryfon, A. \& Hyde, K.L., 2012, 'Auditory-musical processing in autism spectrum disorders: A review of behavioural and brain imaging studies', The Neurosciences and Music: Learning and Memory 4, 325-331.

Patel, A.D., 2007, Music, language and the brain, Oxford University Press, New York.

Paul, R., Augustyn, A., Klin, A. \& Volkmar, F.R., 2005, 'Perception and production of prosody by speakers with autism spectrum disorders', Journal of Autism and Developmental Disorders 35, 205-220. http://dx.doi.org/10.1007/s10803-004-1999-1

Prelock, P.J. \& Nelson, N., 2012, 'Language and communication in autism: An integratedview', Paediatric Clinic North America 59, 129-145. http://dx.doi. org/10.1016/j.pcl.2011.10.008

Sandiford, G.A., Mainess, K.J. \& Daher, N.S., 2013, 'A pilot study on the efficacy of melodic based communication therapy for eliciting speech in nonverbal children with autism', Journal of Autism and Developmental Disorders 43, 1298-1307. http://dx.doi.org/10.1007/s10803-012-1672-z

Schafer, E.C., Mathews, L., Mehta, S., Hill, M., Munoz, A., Bishop, R. et al., 2013 'Personal FM systems for children with autism spectrum disorders (ASD) and/ or attention-deficit hyperactivity disorder (ADHD): An initial investigation',
Journal of Communication Disorders 46, 30-52. http://dx.doi.org/10.1016/j. jcomdis.2012.09.002

Schiavetti, N., \& Metz, D.E., 2006, 'Evaluating Research in Communicative Disorders', 5th ed., Pearson Education, Inc.

Shipley, K.G. \& McAfee, G., 2009, Assessment in speech-language pathology: A resource manual, Cengage Learning, Boston, MA.

Smith, A. \& Robb, M., 2005, 'Durational characteristics of newly-learned trochees and iambs in children with and without speech delays', Clinical Linguistics \& Phonetics 19, 1-14. http://dx.doi.org/10.1080/0269920042000193580

Smith, T., Scahill, L., Dawson, G., Guthrie, D. \& Lord, C., 2007, ‘Designing research studies on psychosocial interventions in autism', Journal of Autism and Developmental Disorders 37, 354-366. http://dx.doi.org/10.1007/s10803-006-0173-3

Thaut, M.H., 2003, 'Rhythmic intervention techniques in music therapy with gross motor dysfunctions'. The Arts in Psychotherapy 15, 127-137. http://dx.doi. motor dysfunctions', The Arts in
org/10.1016/0197-4556(88)90020-2

Tomchek, S.D. \& Dunn, W., 2007, 'Sensory processing in children with and without Autism: A comparative study using the short sensory profile', American Journal of Occupational Therapy 61, 190-200. http://dx.doi.org/10.5014/ajot.61.2.190

Uys, C.J.E., 2002, Validation of a play package to facilitate the development of communication-related skills, Postgraduate research report, University of Pretoria, Pretoria, South Africa.

Veness, C., Prior, M., Bavin, E., Eadie, P., Cini, E. \& Reilly, S., 2012, 'Early indicators of autism spectrum disorders at 12 and 24 months of age: A prospective, longitudinal comparative study', Autism 16, 163-177. http://dx.doi. org/10.1177/1362361311399936

Volkmar, F., Chawarska, K. \& Klin, A., 2005, 'Autism in infancy and early childhood' Annual Review of Psychology 56, 315-336. http://dx.doi.org/10.1146/annurev. psych.56.091103.070159

Wagner, M. \& Watson, D.G., 2010, 'Experimental and theoretical advances in prosody: A review', Language and Cognitive Processes 25, 905-945. http://dx.doi. org/10.1080/01690961003589492

Wan, C.Y., Bazen, L., Baars, R., Libenson, A., Zipse, L., Zuk, J. et al., 2011, 'Auditorymotor mapping training as an intervention to facilitate speech output in nonmotor mapping training as an intervention to facilitate speech output in nonverbal children with autism: A proof of concept
http://dx.doi.org/10.1371/journal.pone.0025505

White, S., Keonig, K. \& Seahill, L., 2006, 'Social skills development in children with autism spectrum disorders: A review of intervention research', Journal of Autism and Developmental Disorders 37, 1858-1868. http://dx.doi.org/10.1007/s10803and Develop $0320-x$

Whitman, T.L., 2004, The development of autism: A self-regulatory perspective, Jessica Kingsley Publishers, London.

Williams, M., Tutty, L.M. \& Grinnell, L.M., 1995, Research in social work: An introduction, 2nd edn., F. E. Peacock Publishers, Itasca.

Williams, S.K., Johnson, C. \& Sukhodolsky, D.G., 2005, 'The role of the school psychologist in the inclusive education of school-age children with autism spectrum disorders', Journal of School Psychology 43, 117-136. http://dx.doi. org/10.1016/j.jsp.2005.01.002

Wing, L., 1988, The Autistic Spectrum: A guide for parents and professionals, Constable, London.

Zager, D.B., 2005, Autism spectrum disorders: Identification, education and treatment, 3rd edn., Taylor and Francis Group, Routledge, London. 


\section{Appendix 1}

Prosodically Varied Speech (PVS) description and procedures (adapted from the Melodic Intonation Therapy (MIT) programme from Helm-Estabrooks et al. 1989)

The original programme of music intonation therapy was originally designed to lead non-fluent aphasic patients from

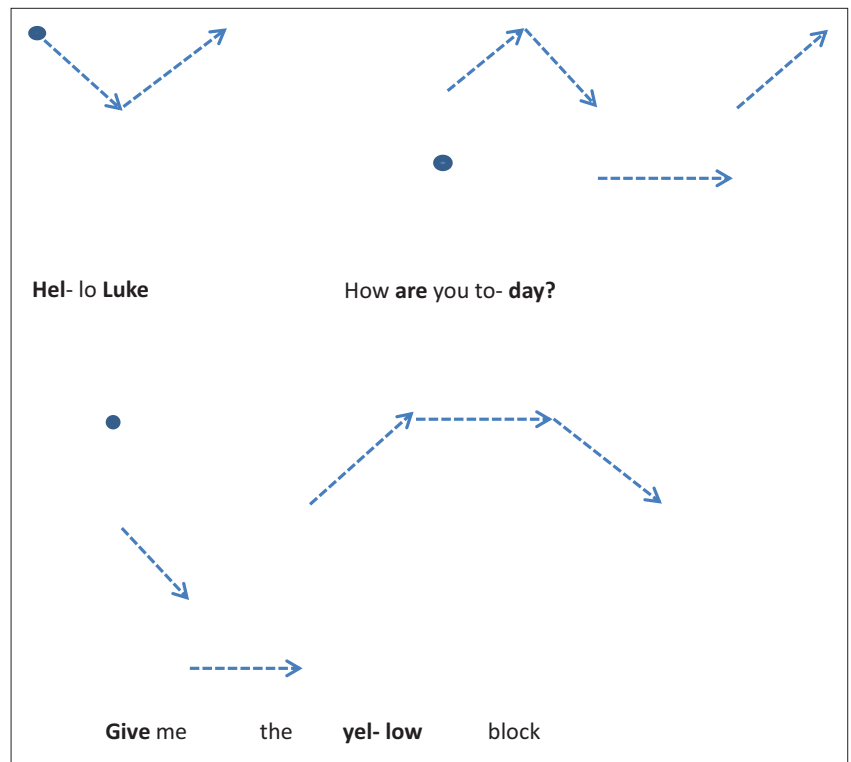

Source: Adapted from Helm-Estabrooks, N., Nicholas, M. \& Morgan, A., 1989, Melodic Intonation Therapy, Pro-Ed., Inc. Austin, TX

FIGURE 1-A2: Phrases are intoned on just two pitches; melodic contour is determined by the natural prosody of speech (e.g. stressed syllables are sung on the higher of the two pitches). intoning simple, 2-3 syllable phrases, to speaking phrases of 5 or more syllables across three levels of treatment. PVS does not include three levels of treatment and only utilises two prosodic aspects namely pitch (high or low notes) and stress variation. Phrases are intoned on just two pitches; stress is determined by the phrases' natural prosody (e.g. stressed syllables are sung on the higher of the 2 pitches, unaccented syllables on the lower pitch [Figure 1]). 